\title{
DIAGNÓSTICO DA GESTÃo DE POLÍTICA PÚBLICA AMBIENTAL DOS RESÍDUOS DE EQUIPAMENTOS ELETROELETRÔNICOS DO MUNICÍPIO DE CUBATÃO/SP
}

\author{
DIAGNOSIS OF THE MANAGEMENT OF ENVIRONMENTAL PUBLIC POLICY OF WASTE OF \\ ELECTRONIC EQUIPMENT OF THE MUNICIPALITY OF CUBATÃO/SP
}

\author{
Paulo Roberto Pereira dos Santos ${ }^{a}$, Maria Lourdes Leite Moraes ${ }^{a}$ \\ aUniversidade Federal de São Paulo \\ mIllmoraes@unifesp.br; paulosophia@terra.com.br
}

Submissão: 20 de setembro de 2021 Aceitação: 13 de dezembro de 2021

\section{Resumo}

Os Resíduos de Equipamentos Eletroeletrônicos (REEE) têm se apresentado como uma problemática contemporânea que exige distinta atenção dos setores públicos e privados. Apesar da Política Nacional de Resíduos Sólidos (PNRS) instituir a responsabilidade compartilhada sobre os REEE, os municípios brasileiros ainda não dispõem de políticas municipais e/ou ações para realizar o descarte e a logística reversa de maneira correta. Considerando esta premissa, o objetivo deste trabalho foi diagnosticar a situação da gestão pública ambiental de REEE no município de Cubatão/SP. A metodologia consistiu no levantamento bibliográfico e análise documental da legislação nacional e municipal, de entrevista semiestruturada com 0 gestor da secretaria de Meio Ambiente da prefeitura local e da análise de conteúdo de informações obtidas junto ao Grupo de Atuação Especial de Defesa do Meio Ambiente (GAEMA/MPSP) e junto à Agência Metropolitana da Baixada Santista (AGEM). Foi feita também uma coleta de dados quantitativos junto às lojas varejistas do município. Estas informações permitiram avaliar a existência de diretrizes e inquéritos civis do município quanto aos REEEs, dos indicadores locais de coleta, tratamento e destinação dos materiais triados nas cooperativas e da comercialização de Equipamentos Eletroeletrônicos (EEE) em um determinado período, a fim de projetar a geração de REEE. Os resultados evidenciaram a ausência de ações, projetos, campanhas, educação ambiental e leis, que em suma compreendem o conjunto das políticas públicas dos REEE no município, assim como a falta de ações junto ao comércio a fim de fomentar e instruir uma política de logística reversa. Somado a isso, os REEE não são recebidos e/ou tratados pelas cooperativas municipais. Evidenciadas as vulnerabilidades, foi redigido e aprovado um projeto de lei junto à Câmara Municipal para que, utilizando do recurso disposto nas políticas públicas de comando e controle, o município pudesse legislar diretamente sobre o REEE e nortear o planejamento de novas ações.

Palavras chave: REEE; diagnóstico; gestão pública; Cubatão.

\section{Abstract}

Waste Electrical and Electronic Equipment (WEEE) has emerged as a contemporary issue that requires different attention from the public and private sectors. Despite the National Solid Waste Policy (PNRS) instituting shared responsibility for WEEE, Brazilian municipalities still do not have municipal policies and/or actions to carry out the correct disposal and reverse logistics. Considering this premise, the objective of this work was to diagnose the situation of public environmental management of WEEE in the city of Cubatão/SP. The methodology consisted of a bibliographic search and documental analysis of national and municipal legislation, a semi-structured interview with the manager of the Environment Secretariat of the local city hall and the content analysis of information obtained from the Special Action Group for the Defense of the Environment (GAEMA /MPSP) and with the Metropolitan Agency of Baixada Santista (AGEM). Quantitative data was also collected from retail stores in the city. This information allowed us to assess the existence of 
guidelines and civil inquiries in the municipality regarding WEEE, local indicators of collection, treatment and disposal of sorted materials in cooperatives and the sale of Electrical and Electronic Equipment (EEE) in a given period, in order to project the generation of WEEE. The results showed he absence of actions, projects, campaigns, environmental education and laws, which comprise the set of public policies for WEEE in the municipality, as well as the lack of actions with commerce in order to promote and instruct a reverse logistic policy. In addition, WEEE is not received and/or treated by municipal cooperatives. Once the vulnerabilities were highlighted, a law project was drafted and approved by the City Council so that, using the provisions of public command and control policies, the municipality could legislate directly on WEEE and guide the planning of new actions.

Keywords: WEEE; diagnosis; public administration; Cubatão

\section{INTRODUÇÃO}

O homem do século XXI está frequentemente conectado, entretido no mundo virtual e, para se ter acesso a este mundo, faz-se necessário o uso de recursos materiais que lhe permitam ingressar neste cenário. Para isso, a posse de equipamentos de tecnologia da informação é essencial. Notebooks, tablets, smartphones, desktops, videogames, são alguns equipamentos eletroeletrônicos que tornam a vida do homem contemporâneo conectada ao mundo. Porém, o ciclo de vida dos equipamentos tecnológicos está cada vez mais curto, seja pelo marketing que impregna o mercado, seja pela obsolescência deles. Xavier et al. (2014) explicam que o consumo vertiginoso de EEE numa escala global está atrelado à sensação de conforto e segurança; todavia a etapa pós-consumo demanda atenção especial a fim evitar danos ao meio ambiente e à saúde pública. Segundo Miguez (2010) aproximadamente $75 \%$ dos EEE antigos estão armazenados nas residências, gerando acúmulo, pois os consumidores não sabem como descartálos, devido ao desconhecimento de locais ou políticas para descarte ambientalmente correto. De fato, a gestão dos resíduos de equipamentos eletroeletrônicos (REEE), é um desafio presente e permanente e que pode agravar-se à medida que ações legais e efetivas se tornam morosas ou insuficientes.

Equipamentos eletroeletrônicos são todos aqueles produtos cujo funcionamento depende do uso de corrente elétrica ou de campos eletromagnéticos. Esses são classificados em quatro categorias: linha branca, marrom, azul e verde, sendo que os equipamentos de tecnologia fazem parte da linha verde (ABDI, 2013). No Brasil, o impulso inicial da indústria de EEE ocorreu entre 1957 e 1975, com a criação da Zona Franca de Manaus, fomentando assim um modelo de integração produtiva na Amazônia Ocidental, o que viabilizou o desenvolvimento econômico do país e fomentou a produção de EEE. Em 1975 o II Plano Nacional de Desenvolvimento favoreceu em larga escala o incentivo à produção eletrônica. $\mathrm{Na}$ década de 1990, o governo abriu o mercado brasileiro com a isenção do IPI - Imposto sobre Produtos Industrializados e consequentemente cresceu a cadeia de produção do segmento de EEE no país, envolvendo a população e intensificando a relação de oferta e demanda. (ABINEE, 2008)

Segundo dados da Associação Brasileira da Indústria Elétrica e Eletrônica (ABINEE, 2020), o mercado oficial de telefones celulares (smartphones e feature phones ou tradicionais) apresentou leve oscilação entre 2015 e 2019 no que diz respeito ao total de aparelhos comercializados em milhões de unidades. No período avaliado, destaca-se o maior volume de vendas em 2015 e 2017, que somadas correspondem a 101,89 milhões de aparelhos. Já a maior variação negativa pode ser identificada entre 2017 e 2018, com redução de 3,75 milhões de aparelhos ou queda no volume de vendas em $7,4 \%$. A partir destes dados é latente o fenômeno do consumo em busca das inovações que o mercado e a tecnologia frequentemente oferta e instiga. Ademais, números divulgados pela Agência Nacional de Telecomunicações (Anatel), no Relatório Panorama Setorial de Telecomunicações, o Brasil registrou 226,7 milhões de linhas móveis em operação em dezembro de 2019 (ANATEL, 2019). Segundo a Agência Brasil (2021), em 2019, a população absoluta no Brasil era de aproximadamente 210 milhões de pessoas. Comparando os dados supracitados, é possível concluir que há mais de uma linha móvel em uso por habitante. O relatório da Global E-Waste Monitor, que publica os dados qualitativos e quantitativos sobre a gestão de 
REEE no mundo, indica que o Brasil é o segundo maior gerador de REEE das Américas, passando de 1,5 t/ano para 2,1 t/ano, um aumento de aproximadamente 40\% (BALDÉ, 2017). Já em 2020, entre os países da América do Sul, o Brasil computa a média de $9,1 \mathrm{~kg} /$ per capita de REEE (FORTI, 2020).

Considerando não apenas o produto final, mas toda cadeia de produção de um eletroeletrônico genérico, da extração da matériaprima, processamento, montagem, embalagem, transporte, distribuição e por fim, a comercialização, é evidente que a posse de determinado bem, muito mais do que promover o ciclo econômico, fere em larga escala o meio ambiente, uma vez que os REEE podem conter, além de objetos de valor como ouro, prata ou cobre, metais que são perigosos para a saúde e para o meio ambiente, como mercúrio, cádmio, chumbo, selênio ou arsênico. Estes metais presentes nos REEE, quando derretidos e/ou queimados com 0 restante do lixo podem contaminar o ar, a terra e a água. (FERNANDÉZ et al., 2016). Um cenário crítico desta contaminação pode ser visualizado através da bioacumulação. Metais perigosos descartados de maneira incorreta em solo ou águas podem ser absorvidos por peixes e/ou vegetação, se acumulando no tecido animal ou vegetal. À medida que a cadeia alimentar progride, a concentração destes metais aumenta, resultando em maior perigo à saúde humana e ao meio ambiente. (FERNANDÉZ, et al, 2016). Os impactos à saúde causados por REEE devido à sua incorreta destinação podem prejudicar sistemas e causar doenças no organismo humano, reduzindo sua qualidade de vida e provocando até mesmo óbitos.

No Brasil, há legislações que buscam comprometer-se com o meio ambiente e suprir as demandas de normatização quanto ao tratamento dos REEE. Como destaque, cabe ressaltar a Lei Federal 12.305/2010 (BRASIL, 2010), que institui a Política Nacional de Resíduos Sólidos (PNRS) que reúne um conjunto de princípios, objetivos, instrumentos, diretrizes e metas do Governo Federal e também atribuem responsabilidades conjuntas ou isoladas aos entes públicos estaduais e municipais. $O$ artigo 10 da lei supracitada incumbe aos municípios a gestão integrada dos resíduos sólidos gerados no respectivo território, assentando assim a tutela e gestão desta tarefa. A própria PNRS caracteriza os REEE como nocivos, tornando necessária a elaboração de um sistema que favoreça o correto descarte e/ou destinação final. (BRASIL, 2010). De modo geral o Art. 30 da PNRS (BRASIL, 2010), institui a responsabilidade compartilhada pelo ciclo de vida dos produtos, tutelando fabricantes, importadores, distribuidores, comerciantes, consumidores e responsáveis pelo serviço público de limpeza urbana às atribuições e objetivos desta legislação. Já de modo específico no Art. 33 e sua regulamentação dada pelo Decreto Federal 9.177/2013, tornam fabricantes, importadores, distribuidores e comerciantes de produtos eletroeletrônicos e seus componentes sujeitos à logística reversa obrigatória.

Xavier et al. (2014) ressaltam que os resíduos tecnológicos representam um considerável passivo ambiental e ao mesmo tempo um nicho de mercado pouco explorado e/ou atendido pelos fabricantes. Tal demanda implica em conhecimento e tecnologia para que haja uma satisfatória gestão ambiental.

O objetivo ecológico da logística reversa pós-consumo retrata preocupações nos processos produtivos, bem como fomenta a mudança de comportamento dos consumidores e da sociedade civil para abrandar os impactos ambientais resultantes dos processos industriais e de exploração de matéria-prima virgem, sempre lembrando que esta prática tem fins econômicos e sociais.

Destarte o Art. 18 da PNRS quando trata dos Planos de Gestão Integrada dos Resíduos Sólidos, concede aos municípios e elaboração de projeto próprio (BRASIL, 2010). Tal enredo garante autonomia de gestão à municipalidade para que trate do assunto conforme as necessidades locais. O termo gestão está relacionado à amplitude, sugere ao administrador aquilo que deve ser feito dentro de uma visão ampla. O gerenciamento já implica no 'como fazer', inserem-se aqui aspectos operacionais (Massukado, 2004). Da mesma maneira, a PNRS em seu Art. 3o, explicita a distinção entre gestão e gerenciamento. No primeiro elenca que são ações que consideram as dimensões política, econômica e ambiental, por exemplo, a fim de encontrar soluções para os resíduos sólidos numa perspectiva de desenvolvimento sustentável. Endossa Chanlat (1999), gestão é "um conjunto de práticas e de atividades fundamentadas sobre certo número de princípios que visam uma finalidade [...]." No segundo, a execução é o destaque. Como relata ao afirmar que gerenciar implica em ações exercidas de coleta, transporte, transbordo e 
outras. Ou seja, gerenciamento resulta em atividade operacional, atividade de campo implementada; a gestão engloba a atividade da normatização e a tomada de decisões políticas.

Para Seiffert (2009), o processo de consolidação da gestão ambiental ocorre por meio de um diagnóstico (características atuais da situação problema), a fim de definir seus objetivos e prognósticos em razão dos instrumentos de gestão empregados, de tal maneira que se encontre um gap ou diferença entre a situação desejada e o cenário atual. Certamente a gestão pública ambiental associada a um processo de administração utiliza, dentre outros meios e, inegavelmente estratégico, os caminhos oferecidos pelas políticas públicas. Segundo Bucci (2006) "Políticas Públicas é um conjunto de medidas articuladas, cujo escopo é dar impulso, isto é, movimentar a máquina do governo, no sentido de realizar algum objetivo de ordem pública ou concretizar um Direito".

Segundo Rua (2014) a arena das políticas públicas organiza-se em quatro áreas: Políticas Distributivas, Políticas Redistributivas, Políticas Regulatórias e Políticas Constitucionais. Não é da natureza deste estudo dissecar cada um destes conceitos, entretanto, serve para indicar que dentro das Políticas Regulatórias encontraremos os instrumentos da política ambiental. Moura (2016) classifica os instrumentos de política ambiental em quatro tipos: I- instrumentos regulatórios ou de comando e controle; IIinstrumentos econômicos; III- instrumentos de cooperação e acordos voluntários; e, IV instrumentos de informação. $E$ reitera afirmando que o conjunto de instrumentos disponíveis para o desenvolvimento de políticas públicas de meio ambiente é bastante extenso, de tal maneira que cada instrumento tem sua particularidade, vantagens e desvantagens, que devem ser bem conhecidos a fim de escolher a melhor das alternativas para determinado cenário. Para enfatizar e referenciar, a própria PNRS, por exemplo, é um instrumento de comando e controle e prevê dezessete itens para isso.

Nesse sentido cabe destacar o entendimento de Field et al. (2014) de que "a abordagem de comando e controle de políticas públicas é aquela em que, a fim de gerar comportamentos socialmente desejáveis, as autoridades políticas simplesmente garantem 0 comportamento por lei e, então, usam qualquer maquinário de fiscalização - polícia, multas - necessário para fazer as pessoas obedecerem à lei". Sobre a mesma abordagem, acrescenta a Agenda 21 Brasileira (BRASIL, 2004) em seu objetivo dezoito, que mudanças na legislação ambiental são necessárias de tal maneira que, introduzindo um novo modelo de gestão ambiental integrado às ações setoriais, constitua mecanismos de controle preventivo e corretivo de atividades e processos, protegendo a capacidade de suporte dos ecossistemas.

Assim, o objetivo deste trabalho foi diagnosticar a situação da gestão pública ambiental de REEE no município de Cubatão/SP e realizar uma intervenção jurídica na legislação municipal.

\section{METODOLOGIA}

Inicialmente foi realizada uma revisão documental da legislação pertinente ao objeto da pesquisa. Foram consultados os seguintes documentos: Constituição Federal de 1988, Leis Federais (12.305/2010) que instituí a Política Nacional de Resíduos Sólidos e lei (9.795/1999) que trata da Política Nacional de Educação Ambiental; Decreto Federal (9.177/2017) que regulamenta 0 Art. 33 da PNRS. Em nível municipal, foram consultadas a Lei Orgânica (Cubatão, 1990) e a Lei (31.140/2010). O acesso aos relatórios da Agência Metropolitana da Baixada Santista (AGEM 2018) e do Plano Regional de Gestão Integrada de Resíduos Sólidos da Baixada Santista, PRGIRS/BS, do Instituto de Pesquisas Tecnológicas do Estado de São Paulo (IPT, 2018), permitiram obter um conjunto conciso de dados dos nove municípios. Dados do Instituto Brasileiro de Defesa do Consumidor (IDEC, 2013), Associação Brasileira de Desenvolvimento Indústria (ABDI, 2013), Associação Brasileira da Indústria Elétrica e Eletrônica ABINEE $(2018,2020)$ e os documentos internacionais E-waste Monitor (BALDÉ et al, 2017), (FORTI et al, 2020) e (UENP, 2009) também foram consultados.

Após a etapa de análise documental, foi realizada uma entrevista semiestruturada junto ao gestor da Secretaria Municipal de Meio Ambiente, inquirindo acerca das ações, programas, projetos e disposições legais voltadas ao trato dos REEE em âmbito local (questões em Material Suplementar). A entrevista foi realizada em 28 de junho de 2019 de modo presencial nas dependências do Palácio Piaçaguera, sede do 
governo municipal. Foi assinado um Termo de Consentimento Livre e Esclarecido (TCLE), a fim de preservar os valores éticos do exercício acadêmico e institucional. As questões foram feitas de modo aberto e categorizadas em cinco categorias. Todas as gravações das entrevistas foram transcritas e avaliadas pela ferramenta análise de conteúdo. As questões formuladas foram divididas em 5 categorias: Identificação, Cooperativas, Logística Reversa, Atendimento à Legislação, Inquéritos Civis (Quadro 1).

Quadro 1: Estrutura de formulação das questões para a entrevista semiestruturada

\begin{tabular}{|c|c|c|}
\hline Categoria & Subcategoria 1 & Descrição \\
\hline & Funcional & $\begin{array}{l}\text { Caracterizada pela descrição da função e tempo de } \\
\text { atuação como gestor da secretaria. }\end{array}$ \\
\hline Identificação & Profissional & $\begin{array}{l}\text { Caracterizada pelo relato de formação técnica, } \\
\text { acadêmica e carreira profissional. }\end{array}$ \\
\hline Cooperativas & Atuação de Cooperativa & $\begin{array}{l}\text { Caracterizada pelos relatos e justificativas da } \\
\text { cooperativa responsável pelos de serviços de coleta } \\
\text { seletiva e destinação final. Também registra a } \\
\text { localização, tipo de atividades e documentação. }\end{array}$ \\
\hline Logística Reversa & $\begin{array}{l}\text { Atividades da Logística } \\
\text { Reversa }\end{array}$ & $\begin{array}{l}\text { Caracterizada por relatos de ações, projetos e/ou } \\
\text { parcerias de logística reversa de matérias diversos. }\end{array}$ \\
\hline $\begin{array}{l}\text { Atendimento } \\
\text { à Legislação }\end{array}$ & $\begin{array}{l}\text { PNRS, Lei Orgânica do } \\
\text { Município e à Política } \\
\text { Nacional de Educação } \\
\text { Ambiental }\end{array}$ & $\begin{array}{l}\text { Caracterizada pelo informe das atividades que } \\
\text { atendem aos dispositivos de competência do } \\
\text { município face à legislação federal e local. Relato da } \\
\text { existência de um núcleo de educação ambiental. }\end{array}$ \\
\hline Inquéritos Civis & $\begin{array}{l}\text { Atos e diligências do } \\
\text { Ministério Público quanto } \\
\text { aos REEE }\end{array}$ & $\begin{array}{l}\text { Caracterizado pela identificação e registro de } \\
\text { apurações junto ao GAEMA/MPSP sobre resíduos de } \\
\text { equipamentos eletroeletrônicos. }\end{array}$ \\
\hline
\end{tabular}

Elaborado pelos autores.

Ademais, foi realizada uma busca junto ao Grupo de Atuação Especial do Meio Ambiente da Baixada Santista, vinculado ao Ministério Público de São Paulo (GAEMA/MPSP) a fim de verificar a existência de algum inquérito civil em relação ao município de Cubatão sobre os REEE. Para a obtenção dos dados, foi feita uma solicitação de informações via email institucional do GAEMA tendo como destinatária a Excelentíssima Promotora de Justiça deste Núcleo de atuação. A troca de informações decorreu ao longo do segundo semestre de 2020.

Foram solicitados também, via ofício ou email, os relatórios de vendas totais de celulares (feature phones), smartphones e tablets no período de 2018-2019, junto às grandes lojas que comercializam equipamentos eletroeletrônicos no município de Cubatão, a fim de se fazer uma previsão da quantidade futura de REEE. O critério para seleção destas lojas foi determinado pela natureza jurídica delas identificadas via consulta online na Receita Federal com o número do Cadastro Nacional de Pessoa Jurídica (CNPJ) obtendo assim o Comprovante de Inscrição e de Situação Cadastral. As lojas selecionadas para a pesquisa foram identificadas como "Sociedade Anônima", ou seja, que tem como principal característica a divisão por ações, o que já demonstra seu porte e importância na economia do município, além de serem varejistas presentes em todo o país.

A projeção da quantidade de metal que acaba virando resíduo foi feita utilizando a métrica do relatório From Waste to Resources da UNEP (2009), onde considerando uma única unidade, cada telefone celular tem aproximadamente: 250 $\mathrm{mg}(\mathrm{Ag}), 24 \mathrm{mg}(\mathrm{Au}), 9 \mathrm{mg}(\mathrm{Pd})$ e $9 \mathrm{~g}(\mathrm{Cu})$. Seguindo este padrão, foram feitas as projeções para os celulares e tablets.

Por fim, foi elaborado pelo autor e protocolado 
junto à Presidência da Câmara de Vereadores de Cubatão, um esboço de Projeto de Lei, abordando o alinhamento da legislação local à PNRS. Foram realizadas no primeiro semestre de 2019 , duas reuniões presenciais junto ao Presidente da Câmara Municipal de Cubatão, onde foi apresentada uma minuta de Projeto de Lei, para que pudesse ser apreciada e, por fim, protocolada e submetida à votação em plenário.

\section{RESULTADOS E DISCUSSÃO}

\subsection{Caracterização da Área de Pesquisa e a Gestão Pública Municipal de REEE}

Os municípios que compreendem a Região Metropolitana da Baixada Santista/SP são nove: Bertioga, Guarujá, Cubatão, Santos, São Vicente, Praia Grande, Mongaguá, Itanhaém e Peruíbe. A cidade de Cubatão, próxima ao Porto de Santos e ao sistema rodoviário Anchieta-Imigrantes, sendo detentora de um dos maiores polos petroquímicos da América Latina e portadora de mananciais que abastecem a Região Metropolitana da Baixada Santista (RMBS) possui em seu entorno uma flora distinta presente na Serra do Mar (AGEM, 2018). O município de Cubatão, como o espaço principal de investigação deste trabalho, requer uma visão sistêmica que agrega a questão da malha rodoviária e ferroviária $e$ as inúmeras oportunidades de emprego que o município oferece. Esse contexto foi favorável para a atração e retenção de capital humano e financeiro, bem como a promoção de uma intensa migração regional a fim de ocupar os postos de trabalho no início da industrialização na década de 1950. Atualmente a Cidade de Cubatão conta com empresas de grande porte como Yara Fertilizantes, Refinaria Presidente Bernardes e a Companhia Brasileira de Estireno (AGEM, 2018).

Com um PIB per capita de $\mathrm{R} \$ 141.290,89$, Cubatão é o $12^{\circ}$ município com maior valor no
Estado de São Paulo (SEADE, 2017), o que pode ser referência para justificar 0 aumento da capacidade de consumo e consequentemente a geração de REEE. O referido indicador econômico certamente é analisado pela administração municipal e com um olhar ímpar pela secretaria de Meio Ambiente, que é a pasta responsável pela gestão, fiscalização e implementação de políticas públicas ambientais.

No que tange ao atendimento à legislação, o município de Cubatão não possui lei ou normatização específica que trate dos REEE bem como não parece cumprir as responsabilidades atribuídas pelo Art. 18 da PNRS (2010) quando trata do Plano Municipal de Gestão Integrada de Resíduos Sólidos (Quadro 2 e Inquérito Civil - IC 27/10 GAEMA/BS).

Agregando dados à verificação da gestão pública municipal de REEE, uma pesquisa documental nos conduziu a uma Lei Ordinária (CUBATÃO, 2010) Municipal 3.410 de 17 de agosto de 2010, que está em vigor que, "Permite à Associação Beneficente de Catadores de Material Reciclável da Baixada Santista - ABCMARBAS, o uso de bem do Patrimônio Público Municipal e dá outras providências". Para endossar a existência e funcionamento da cooperativa, foi verificado junto a um recurso de consulta pública da Receita Federal o comprovante de inscrição e situação cadastral da pessoa jurídica sob o CNPJ 04.521.916-001/48, o que nos forneceu atestado de regularidade e o logradouro da cooperativa.

Aditada a isso, a consulta em relatórios recentes como o Plano Regional de Gestão Integrada de Resíduos Sólidos da Baixada Santista (PRGIRS/BS) e no Diagnóstico da Geração e Gerenciamento de Resíduos Sólidos na Região Metropolitana da Baixada Santista (AGEM, 2018), forneceram dados sobre a situação dos materiais triados nas cooperativas de Cubatão (Quadro 2).

Quadro 2 - Tratamento e destinação dos materiais triados nas Cooperativas

\begin{tabular}{|l|l|}
\hline Município & Cubatão \\
\hline Cooperativa & $\begin{array}{l}\text { Associação Beneficente dos Catadores de Materiais Recicláveis da Baixada Santista } \\
\text { (ABC Marbas) }\end{array}$ \\
Materiais & PET incolor, PET colorido, PET marrom, PEAD incolor, PEAD colorido, PEAD outros, \\
Comercializados & $\begin{array}{l}\text { PVC incolor, PVC colorido, PEBD incolor e colorido, PP incolor e colorido. Outros } \\
\text { plásticos coloridos e incolor, papelão, papel branco, colorido e misto, metais ferrosos e } \\
\text { não ferrosos, vidro colorido e incolor }\end{array}$
\end{tabular}

Elaborada pelos autores. Adaptada de (AGEM, 2018). 
A partir da análise das informações obtidas nas entrevistas, observamos que não existe nenhuma ação específica para a coleta e tratamento de EEE pós-consumo no município de Cubatão até o momento. Atualmente existem somente Ecopontos em parceria com o comércio local que coletam pilhas, baterias, óleo de cozinha e lâmpadas, além de um sistema de coleta seletiva realizada por uma cooperativa. Porém, naquele momento o gestor não dispunha de certeza quanto à coleta e tratamento de REEE. Todavia o Quadro 2 registra a ausência de REEE entre os materiais coletados pela cooperativa, o que implica num descarte doméstico e comercial irregular, sendo certamente direcionado ao aterro sanitário que fica no município vizinho de Santos/SP.

Sobre a questão da educação ambiental, foi relatado que o dispositivo legal no Art. 193 da Lei Orgânica (Cubatão, 1990) do município de Cubatão, que trata sobre a obrigatoriedade da matéria "Meio Ambiente" nas escolas geridas pela municipalidade no âmbito do ensino fundamental, não existe no currículo, logo, este instrumento de educação formal e cidadã apresenta-se ineficiente e não condizente com a necessidade de conscientização da população. Acrescido a estas informações, foi relatado na entrevista a ciência de inquéritos civis junto ao GAEMA-MPSP acerca dos REEE envolvendo Cubatão e outros municípios da Região Metropolitana da Baixada Santista.

Comparando as informações adquiridas pela entrevista com os dados documentais, podemos afirmar que não há atividade de coleta, tratamento ou destinação final de REEE no município de Cubatão, demonstrando assim uma lacuna nas atividades da gestão pública ambiental.

A consulta ao PRGIRS/BS e no Diagnóstico da Geração e Gerenciamento de Resíduos Sólidos na Região Metropolitana da Baixada Santista (AGEM 2017; 2018), forneceram dados para aferir e avaliar a situação de descarte de REEE na RMBS e especificadamente no município de Cubatão.

Quadro 3: Agravos à saúde provocados pelo descarte incorreto de REEE

\begin{tabular}{|c|c|c|c|c|c|c|c|c|c|c|}
\hline Resíduos para Coleta & Responsável & Bertioga & Cubatão & Guarujá & $\begin{array}{c}\text { Ita } \\
\text { nhaém }\end{array}$ & $\begin{array}{l}\text { Monga } \\
\text { guá }\end{array}$ & Peruíbe & $\begin{array}{c}\text { Praia } \\
\text { Grande }\end{array}$ & Santos & \begin{tabular}{|c|} 
São \\
Vicen \\
te
\end{tabular} \\
\hline $\begin{array}{l}\text { Baterias inservíveis } \\
\text { de chumbo ácido }\end{array}$ & INPEV & $\mathrm{CV}$ & CV & CV & CV & CV & CV & CV & CV & CV \\
\hline $\begin{array}{c}\text { Pilhas e batérias } \\
\text { portáteis }\end{array}$ & ABINEE & PP & PP & PP & PP & PP & PP & PP & PP & PP \\
\hline Pneus & RECICLANIP & PP & PP & PP & PP & PP & PP & PP & PP & $\mathrm{SI}$ \\
\hline $\begin{array}{c}\text { Produtos } \\
\text { eletroeletrônicos de uso } \\
\text { doméstico }\end{array}$ & $\begin{array}{l}\text { Green } \\
\text { Eletron }\end{array}$ & SAl & SAI & SAI & SAI & SAI & SAl & SAI & SAI & SAI \\
\hline Telefonia móvel & $\begin{array}{l}\text { SINDITE- } \\
\text { LEBRASIL }\end{array}$ & CV & CV & CV & $\mathrm{CV}$ & CV & $\mathrm{CV}$ & CV & $\mathrm{CV}$ & CV \\
\hline
\end{tabular}

PP- Ações implantadas por meio de Parcerias Públicas CV- Ações implantadas pelo Comércio Varejista SAl- Sem Ações Implantadas. * No Plano regional de gestão integrada de resíduos sólidos da Baixada Santista, PRGIRS/BS/2018, o município de Santos consta com PP quanto aos produtos eletroeletrônicos de uso doméstico.

Elaborado pelos autores. Adaptado de (AGEM, 2018).

Considerando que o principal objeto de pesquisa deste trabalho são os REEE, também se constatou que quanto ao sistema de coleta dos resíduos passíveis de logística reversa, agora especificadamente quanto aos REEE, não há ações implantadas em nenhum dos municípios da RBMS, que pudessem conferir atendimento ao preconizado na PNRS, revelando assim descumprimento da letra da lei e deficiência na gestão ambiental voltada a este tema.
Ademais, cabe ressaltar a dinâmica da responsabilidade compartilhada, a fim de que numa teia colaborativa, a sociedade e suas instituições possam exercer suas respectivas atribuições, contribuindo assim para uma melhor qualidade de vida de todos os envolvidos. Acerca da responsabilidade compartilhada, a PNRS (BRASIL, 2010) no inciso XVII do artigo $3^{\circ}$ assim inferi:

\section{Conjunto de atribuições}




\begin{abstract}
individualizadas e encadeadas dos fabricantes, importadores, distribuidores e comerciantes, dos consumidores e dos titulares dos serviços públicos de limpeza urbana e de manejo dos resíduos sólidos, para minimizar o volume de resíduos sólidos e rejeitos gerados, bem como para reduzir os impactos causados à saúde humana e à qualidade ambiental decorrentes do ciclo de vida dos produtos, nos termos desta Lei (grifo nosso).
\end{abstract}

Endossando a ideia, no esquema de responsabilidade compartilhada pelo ciclo de vida do produto trazido pela PNRS, os consumidores deverão efetuar, após o seu uso, a devolução dos produtos eletroeletrônicos e seus componentes, aos comerciantes ou distribuidores. Estes, por sua vez, deverão devolvê-los aos fabricantes ou importadores de tais produtos, os quais promoverão a destinação final ambientalmente adequada de seus resíduos eletroeletrônicos, e a disposição adequada de seus rejeitos. (XAVIER et al., 2014).

\subsection{Apontamentos do exame das informações colhidas junto ao GAEMA-MPSP}

O GAEMA-MPSP foi instituído pelo ato normativo 552/08 de 4 de setembro de 2008 e tem como missão a identificação, prevenção e repressão das atividades causadoras de degradação ambiental no Estado de São Paulo. Sua atribuição implica em oficiar nas representações, inquéritos civis, procedimentos preparatórios de inquéritos civis para a defesa e proteção dos bens ambientais nos temas eleitos como prioritários. É um serviço público e de acesso comum.

O feedback da secretaria e da Exma. Promotora, nos permitiu identificar o Inquérito Civil (IC) $27 / 10$ que tem como objeto: "Descarte de resíduos sólidos tecnológico/eletrônicos envolvendo os municípios da Baixada Santista, exceto o município de Santos, por já existir inquérito civil sobre o assunto naquela cidade". Ressalta-se que o título do IC, tem exceção quanto ao município de Santos, por já possuir IC local sobre $o$ assunto.

É válido registrar que um IC é instaurado quando há fortes evidências de que um direito coletivo, social ou individual indisponível foi lesado ou é iminente seu acontecimento. A Constituição Federal (1988) no Art. 5 discorre sobre os direitos coletivos, e ali está o meio ambiente. Independente da parte que fez a denúncia e moveu a ação, cabe ao cidadão comum, verificar, preservar e garantir um meio ambiente saudável. Se por vezes a educação ambiental na esfera pública é desprestigiada, os vieses jurídicos podem ser de grande valia e amparo para garantir a devida atenção a problemas de ordem ambiental e outras temáticas.

O referido processo legal ainda não consta como concluído, logo os citados, inclusive Cubatão/SP, carecem da apresentação das ações que possam atender, mitigar ou resolver a questão dos REEE. Acrescido a isso, a pesquisa documental no PRGIRS/BS (AGEM, 2018) replicou como resultado a ausência de ações implantadas quanto à logística reversa e o sistema de coleta de produtos eletroeletrônicos de uso doméstico.

\subsection{Análise da amostra de venda varejista e prognóstico de geração de REEE}

Existem atualmente três grandes lojas varejistas que comercializam EEE em Cubatão. O número total de vendas de EEEs pode ser um indicador da quantidade de REEE produzida. Segundo o Instituto Brasileiro de Defesa do Consumidor (IDEC), o ciclo de vida e o tempo médio de posse de smartphones, celulares e tablets é de aproximadamente 3 (três) anos (IDEC, 2013). Considerando o tempo de vida útil destes equipamentos é possível fazer uma predição a curto prazo desta demanda. Das três lojas contactadas, apenas duas delas nos enviaram o relatório de vendas de smartphones, celulares e tablets, dos anos de 2018 e 2019, dados mostrados na Tabela 1.

Segundo Carvalho (2012), o montante de aproximadamente seis mil celulares equivale a uma tonelada destes equipamentos. Logo, o total de aparelhos comercializados indicado na Tabela 1 , resultará em pouco mais de quatro toneladas de REEE entre 2021 e 2022, conforme ciclo de vida útil apontado pelo IDEC. Lembrando que a amostra está localizadas no município, o que certamente resulta num número muito maior de eletroeletrônicos se considerarmos o cenário de compra e venda em outras cidades da região, bem 
como aqueles comercializados no mercado cinza e no e-commerce.

Os REEE possuem ainda alto valor agregado. Conforme o relatório From Waste to Resources da UNEP (2009), uma tonelada de telefones celulares sem bateria, possuem em média, $3,5 \mathrm{~kg}$ de prata
$(\mathrm{Ag}), 340 \mathrm{~g}$ de ouro $(\mathrm{Au}), 140 \mathrm{~g}$ de paládio $(\mathrm{Pd}) \mathrm{e}$ $130 \mathrm{~kg}$ de cobre $(\mathrm{Cu})$. Dos três elementos químicos citados, o Pd é o metal comercialmente mais valioso, todavia presente em menor quantidade. $\mathrm{O}$ que deve ser destacado é a grande quantidade de $\mathrm{Cu}$, que é um condutor de eletricidade.

Tabela 1: Quantidade total de vendas de smartphones, celulares e tablets, no período de 2018-2019 e projeção de metais residuais da amostra obtida em duas lojas de Cubatão durante o período em estudo.

\begin{tabular}{c|c|c|c|c}
\hline Loja & $\begin{array}{c}\text { Quantidade total de } \\
\text { vendas (em peças) }\end{array}$ & $\begin{array}{c}\text { Projeção de Prata } \\
(\mathrm{Ag}) \text { em } \\
\text { quilograma }(\mathrm{Kg})\end{array}$ & $\begin{array}{c}\text { Projeção de } \\
\text { Paládio }(\mathrm{Pd}) \text { em } \\
\text { quilograma } \\
(\mathrm{Kg})\end{array}$ & $\begin{array}{c}\text { Projeção de } \\
\text { Cobre }(\mathrm{Cu}) \mathrm{em} \\
\text { quilograma }(\mathrm{Kg})\end{array}$ \\
\hline 1 & 14.870 & 3,7 & 0,133 & 133,8 \\
2 & 10.356 & 2,5 & 0,093 & 93,2 \\
Total & 25.136 & 6,2 & 0,226 & 227 \\
\hline
\end{tabular}

Elaborado pelos autores

Considerando seus impactos ao meio ambiente e à saúde humana e animal, a bioacumulação é um fator relevante, já que muitas vezes estes elementos chegam ao ar quando liberado em processo de combustão, permanecendo na atmosfera até depositar-se no solo onde pode unir-se a matéria orgânica e mineral. Ainda na perspectiva biológica, pode acontecer a biomagnificação, que pode ser definida "como o aumento da concentração dos contaminantes nos tecidos dos organismos à medida que se encontrem em um nível trófico superior."(AZEVEDO, et al., 2003). A exposição humana a metais tóxicos em largo período e quantidade, bem como o consumo das espécies contaminadas pode causar irritações bucais, nasais e oculares, além de dor de cabeça seguida de alterações gastrointestinais e possíveis danos hepático e renal (FERNÁNDEZ et al., 2016). O Quadro 4 mostra os agravos a saúde humana provocados pela exposição a alguns destes metais.

Quadro 4: Agravos à saúde humana provocados pelo descarte incorreto de REEE

\begin{tabular}{|c|c|c|c|c|c|c|c|c|c|c|c|c|}
\hline \multirow[b]{2}{*}{$\begin{array}{l}\text { Elementos } \\
\text { químicos } \\
\text { encontrados } \\
\text { em REEE }\end{array}$} & \multicolumn{6}{|c|}{ Sistemas prejudicados } & \multicolumn{2}{|c|}{ Doenças } & \multicolumn{4}{|c|}{ Órgãos danificados } \\
\hline & 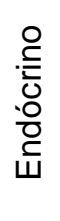 & $\begin{array}{l}\text { O } \\
\text { O } \\
\frac{2}{0} \\
\frac{1}{Z}\end{array}$ & $\begin{array}{l}.0 \\
\frac{0}{0} \\
\frac{0}{0} \\
\frac{0}{5} \\
. \frac{1}{0} \\
0\end{array}$ & 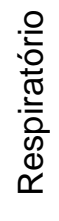 & 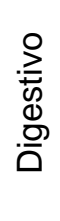 & $\begin{array}{l}\frac{\overline{0}}{0} \\
\frac{7}{0} \\
\frac{0}{0} \\
\frac{0}{0} \\
\simeq\end{array}$ & 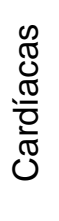 & 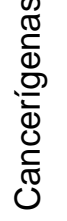 & 을 & $\begin{array}{l}\frac{0}{0} \\
\text { ত্ } \\
\frac{0}{4}\end{array}$ & $\begin{array}{l}0 \\
\text { D } \\
\mathscr{D} \\
\text { OD }\end{array}$ & 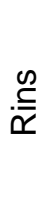 \\
\hline Cádmio & & & & & & & & $x$ & & $x$ & $x$ & $x$ \\
\hline Chumbo & $x$ & $\mathrm{x}$ & $\mathrm{x}$ & & $x$ & $x$ & & $x$ & & $x$ & & $x$ \\
\hline Cobre & & & & & $x$ & & & & & & & \\
\hline Mercúrio & & $\mathrm{x}$ & & $x$ & & & $x$ & & $x$ & & & $\mathrm{X}$ \\
\hline $\begin{array}{l}\text { Retardantes } \\
\text { de chamas }\end{array}$ & $x$ & & & & & $x$ & & & $x$ & & & \\
\hline
\end{tabular}

Adaptado de (NUNES et al. 2017)

Segundo o Fórum Econômico Mundial (2019), os REEE representam cerca de $2 \%$ de todo resíduos sólidos produzidos mundialmente, todavia pode possuir até 60 elementos encontrados na tabela periódica, o que torna os REEE potencialmente nocivos à saúde e ao meio 
ambiente.

Cabe também ressaltar que as baterias de equipamentos eletroeletrônicos portáteis são predominantemente compostas por cádmio (Cd) e lítio (Li). O Cd lançado nos corpos hídricos é retido por plantas aquáticas e terrestres, podendo formar um ciclo de bioacumulação quando concentrado em organismos marinhos que se alimentam destas plantas ou ali vivem (CARDOSO et al., 2001). Por ser um metal muito tóxico a exposição prolongada a este material pode causar dano renal e ósseo, bem como manifestações de vômitos e diarreia (FERNANDEZ et al., 2016). Já o Li se destaca pela sua característica bastante corrosiva. Neste sentido a PNRS (BRASIL, 2010) classifica no Art. 13 os resíduos quanto à periculosidade em razão das características, de inflamabilidade, corrosividade, reatividade, toxicidade, patogenicidade, carcinogenicidade, teratogenicidade e mutagenicidade, apresentando assim significativo risco à saúde pública ou à qualidade ambiental. Estas informações nos permitem evidenciar que a inexistência de ações de coleta de REEE pode decorrer em descarte irregular e certamente na poluição do solo e da água. Somado a isso a possibilidade de queimas destes materiais, acarretaria no lançamento de elementos nocivos no ar, podendo causar moléstias ao sistema respiratório dos indivíduos que porventura inalarem tal fumaça.

Neste sentido, seria interessante reciclar estes REEE a fim de se obter esta importante fonte industrial de elementos químicos. Seja pelo poder público, pela iniciativa privada, Terceiro Setor ou Parcerias Público-Privada (PPP). Os REEE representam uma potencial oportunidade de geração de renda já que, com demonstrado, sua composição é repleta de valor agregado, que instrumentalizado com correta técnica e tecnologia não só tem viabilidade econômica como também o correto descarte e destinação final fomentam o desenvolvimento sustentável e a preservação do meio ambiente.

\subsection{Discussão e elaboração da minuta de projeto de lei.}

Diante dos resultados obtidos e a fim de fomentar a gestão de políticas públicas no município de Cubatão, foi elaborada uma minuta de projeto de lei para promover a coleta e gestão de REEEs. A minuta foi proposta junto ao poder legislativo no dia 22 de abril de 2019, a qual foi submetida à apreciação do Presidente da Câmara Municipal de Cubatão. Após avaliação e prévia de validade de teor jurídico, o referido vereador prontamente compilou a minuta em formato oficial e protocolou no setor de Divisão Legislativa sob a PL - Projeto de Lei 59/2019. Em 30 de abril, foi emitido o Parecer do Procurador Legislativo, que opinou pela constitucionalidade, legalidade e juridicidade do projeto de lei ora apreciado (PL N. 59/2019). Considerando a integralidade do documento, destaca-se a autorização ao Poder Executivo para celebrar parceria com pessoa jurídica fim de celebrar contrato para coleta e destinação final dos REEE; estimula-se a responsabilidade compartilhada de tal modo que as empresas privadas do comércio local possam destacar-se, divulgar e até participar de premiações acerca da Responsabilidade Socioambiental; a criação de programas na educação formal e informal a fim de criar hábitos e atitudes para preservação, conservação e recuperação do meio ambiente e, por fim, um conjunto de penalidades a serem impostas aos infratores no caso de não cumprimento da legislação em pauta.

Assim sendo, o documento foi aprovado em 14 de maio, e em 19 de junho de 2019 foi promulgada a Lei № 4.005 (CUBATÃO, 2019) que "Disciplina o descarte e o gerenciamento de resíduos eletroeletrônicos no município de Cubatão, autoriza o poder executivo a celebrar parceria com pessoa jurídica que faça os serviços de coleta, reutilização, reciclagem, tratamento ou disposição final e dá outras providências".

A presente lei enquadra-se nos instrumentos de comando e controle das políticas públicas outrora citadas e conduz o município de Cubatão a adequações legais em face à PNRS. De certo, não somente uma lei resolverá a questão dos REEE na cidade, mas certamente será um agente motriz para melhorias da gestão e condições dadas à população para tratar os REEEs domiciliares. Ainda, como um grande polo petroquímico, as empresas e indústrias localizadas no município, também poderão se beneficiar desta lei ao descartar seus EEE obsoletos, principalmente os da Linha Verde e Marrom.

Cabe agora aos comerciantes e grandes varejistas locais, estabelecer critérios de recepção dos REEE para fomentar a cadeia de logística reversa, novamente não somente por força da lei, mas também como ações vinculadas à responsabilidade socioambiental empresarial. 


\section{CONCLUSÕES}

Apesar da legislação pertinente acerca dos resíduos eletroeletrônicos (REEE), no Brasil, as prefeituras das cidades ainda carecem de ações para efetivar a logística reversa e o descarte correto destes produtos, especialmente os de linha verde (celulares e tablets), que são comercializados em larga escala, gerando um volume excessivo de REEE.

A gestão pública ambiental no município de Cubatão/SP no que diz respeito aos REEE, pôde ser diagnosticada como deficitária e carente de ações e/ou projetos que viabilizem a proposta de logística reversa prevista na PNRS. Foi possível identificar deficiências tanto na perspectiva ampla, quando observado o Plano Regional de Gestão Integrada de Resíduos Sólidos, como em sentido restrito, ao avaliar o conteúdo da entrevista semiestruturada e identificar a ausência de proposta que trate dos REEE, bem como legislação própria e evidências confirmadas de apuração junto ao Ministério Público. Tamanho imbróglio reflete a necessidade de melhor ordenação de políticas públicas ambientais e eficiente cumprimento das letras das leis.

Ademais 0 esforço para elaboração, protocolo, acompanhamento e promulgação de legislação municipal que tratasse adequadamente dos REEE, logrou exitosa e pode servir de norte para uma nova abordagem da gestão municipal quanto à temática dos REEEs.

Vislumbrando trabalhos futuros, sugere-se 0 acompanhamento estatístico de coleta de REEE pelos grandes varejistas e demais entes descritos na lei, a fim de melhor compilar o volume de REEE produzidos no município e com estes dados, fazer uma avaliação sistêmica que implique em oportunidades de geração de renda e combate à poluição.

\section{AGRADECIMENTOS}

Os autores agradecem à Secretaria de Meio Ambiente da Prefeitura de Cubatão, ao Grupo de Atuação Especial de Defesa do Meio Ambiente (GAEMA/MPSP), à Agência Metropolitana da Baixada Santista (AGEM) e às lojas do comercio varejista de Cubatão, que gentilmente concederam os relatórios de vendas.

\section{REFERÊNCIAS}

A New Circular Vision for Eletronics: Time for a Global Reboot. World Economic Forum ; Platfotm for Accelerating the Circular Economy (PACE) (2019). Disponível em:

https://www3.weforum.org/docs/WEF A New Circular Vision for Electronics.pdf> Acesso em 20 nov. 2019.

ABDI. Agência Brasileira de Desenvolvimento Industrial. Logística Reversa de Equipamentos Eletroeletrônicos - Análise de Viabilidade Técnica e Econômica. Brasília: ABDI, 2013. 179 p.

ABINEE. A Voz da Indústria Elétrica e Eletrônica no Brasil. São Paulo: Bellini Cultural, 2008. 120 p.

.Desempenho Setorial. Disponível em: http://www.abinee.org.br/ abinee/decon/decon15.htm. Acesso em 04 nov. 2018.

Panorama Econômico e Desempenho Setorial 2020. São Paulo: ABINEE, 2020. Disponível em:

http://www.abinee.org.br/programas/50anos/public/pan orama/2020/>. Acesso em 15 ago. 2020.

AGEM. Agência Metropolitana da Baixada Santista. IPT. Instituto de Pesquisas Tecnológicas do Estado de São Paulo. Plano Regional de Gestão Integrada de Resíduos Sólidos da Baixada Santista, PRGIRS/BS [livro eletrônico] / [coordenadoras Fernanda Faria Meneghello, Cláudia Echevenguá Teixeira]. -- São Paulo: IPT - Instituto de Pesquisas Tecnológicas do Estado de São Paulo; Santos, SP : AGEM,IPT, 2018. $386 \mathrm{p}$.

Panorama dos Resíduos Sólidos na RMBS Baixada Santista. (Versão para as oficinas microrregionais. Junho de 2017. Disponível em:< http://www.agem.sp.gov.br/midia/Panorama2.pdf >.

Acesso em: 10 ago.2019

ANA. Agência Nacional de Águas. Atlas Esgotos. Despoluição das Bacias Hidrográficas. Brasília: ANA, 2017. 88 p.

AGÊNCIA BRASIL. Estimativa da população do Brasil passa de 210 milhões, diz IBGE. Disponível em:https://agenciabrasil.ebc.com.br/economia/noticia/2 019-08/estimativa-da-populacao-do-brasil-passa-de210-milhoes-diz-ibge . Acesso em 02 set. 2019.

ANATEL. Agência Nacional de Telecomunicação. Relatório Panorama Setorial: Telecomunicações em Números. Brasília: ANATEL, 2019. Disponível em:< https://www.gov.br/anatel/ptbr/assuntos/noticias/relatorio-anual-de-gestao-2019-jaesta-disponivel>. Acesso em: 28 mai. 2020. 
BALDÉ, C.P.; FORTI V.; GRAY, V.; KUEHR, R.; STEGMANN,P. : The Global E-waste Monitor 2017. United Nations University (UNU), International Telecommunication Union (ITU) \& International Solid Waste Association. Bonn/Geneva/Vienna: ISWA, 2017. $116 \mathrm{p}$.

BRASIL. Agenda 21 brasileira: resultado da consulta nacional / Comissão de Políticas de Desenvolvimento Sustentável e da Agenda 21 Nacional. 2. ed. Brasília : MMA, 2004. Disponível em:< https://www.infraestruturameioambiente.sp.gov.br/educ acaoambiental/prateleira-ambiental/agenda-21brasileira-resultado-da-consulta-nacional-2a-edicao/> Acesso em: 10 out. 2020.

BRASIL. Constituição da República Federativa do Brasil.: Texto constitucional publicado em 5 de outubro de 1988, compilado até a Emenda Constitucional n. 105/2019. Brasília: Senado Federal, Coordenação de Edições técnicas, 2020. Disponível em:<

http://www.planalto.gov.br/ccivil 03/constituicao/constit uicao.htm>. Acesso em 12 mar. 2020.

BRASIL. Decreto Federal n. 9.177. Regulamenta o art. 33 da Lei no 12.305, de 2 de agosto de 2010, que institui a Política Nacional de Resíduos Sólidos, e complementa os art. 16 e art. 17 do Decreto no 7.404 , de 23 de dezembro de 2010 e dá outras providências. Brasília: DOU, 2017. Disponível em:< http://www.planalto.gov.br/ccivil 03/ ato20152018/2017/decreto/d9177.htm>. Acesso em 15 nov. 2018.

BRASIL. Lei Federal n. 12.305 de 12 de agosto de 2010. Institui a Política Nacional de Resíduos Sólidos. Brasília: DOU, 2010. Disponível em: $<$ http://www.planalto.gov.br/ccivil 03/ ato20072010/2010/lei//12305.htm>. Acesso em 15 nov. 2018.

BUCCI. Maria Paula Dallari. Políticas Públicas: reflexões sobre o conceito jurídico. São Paulo: Saraiva, 2006. 310 p.

CARDOSO, Luiza M. N.; CHASIN, Alice A. M. Ecotoxicologia do cádmio e seus compostos. v. 6 Salvador: Centro de Recursos Ambientais, 2001. 122 p.

CARVALHO. Pierre Pereira Morlin de. A importância da elicitação de requisitos de software no escopo das ações desenvolvidas segundo a TI verde. Dissertação (Mestrado em Engenharia Ambiental) Universidade Federal do Rio de Janeiro, Rio de Janeiro, 2012. Disponível em: < https://pea.ufri.br/dissertacoesde-mestrado/>. Acesso em 12 set. 2019.
CHANLAT, Jean-François. Ciências sociais e management: reconciliando o econômico e o social. São Paulo: Atlas, 1999. 100 p.

CUBATÃO. Lei Municipal n. 3.410. Permite à Associação Beneficente de Catadores de Material Reciclável da Baixada Santista - ABCMARBAS, o uso de bem do Patrimônio Público Municipal e dá outras providências. Câmara Municipal de Cubatão: Cubatão, 2010. Disponível em: < https://www.legislacaodigital.com.br/CubataoSP/LeisOrdinarias/3410 >. Acesso em: 21 ago. 2020.

CUBATÃO. Lei Orgânica Municipal. Câmara Municipal de Cubatão: Cubatão, 1990. Disponível em:< https://www.legislacaodigital.com.br/CubataoSP/LeisOrganicas/0>. Acesso em: 08 fev. 2019.

CUBATÃO. Lei Municipal n. 4005. Disciplina o descarte e o gerenciamento de resíduos eletroeletrônicos no município de Cubatão, autoriza o poder executivo a celebrar parceria com pessoa jurídica que faça os serviços de coleta, reutilização, reciclagem, tratamento ou disposição final e dá outras providências. Câmara Municipal de Cubatão: Cubatão, 2019. Disponível em:, https://www.legislacaodigital.com.br/Cubatao-

SP/LeisOrdinarias/4005>. Acesso em: 30 jun. 2019.

FERNANDÉZ, Belén García:; BLANCO, Teresa Boquete. Basura electrónica: um mundo dividido. Madrid: Pigmalión, 2016. 110 p.

FIELD, Barry C.; FIELD, Martha K. Introdução à Economia do Meio Ambiente. 6 ed. Porto Alegre: Bookman, 2014. 394 p.

FORTI, V.; BALDÉ C.P.; KUEHR R.; BEL G. The Global E-waste Monitor 2020: Quantities, flows and the circular economy potential. United Nations University (UNU)/United Nations Institute for Training and Research (UNITAR) - co-hosted SCYCLE Programme, International Telecommunication Union (ITU) \& International Solid Waste Association (ISWA). Bonn/Geneva/Rotterdam, 2020. 120 p.

IDEC. Instituo Brasileiro de Defesa do Consumidor. Ciclo de Vida de Eletrônicos. São Paulo: IDEC, 2013. Disponível em:< http://www.idec.org.br/uploads/testes pesquisas/pdfs/m arket analysis.pdf >. Acesso em 15 ago. 2020.

MASSUKATO, Luciana Miyoko. Sistema de Apoio à Decisão: avaliando cenários de gestão integrada de resíduos sólidos urbanos domiciliares. Dissertação (Mestrado em Engenharia Urbana) - Universidade Federal de São Carlos, São Carlos, 2004. 272 p. 
MIGUEZ, Eduardo Correia. Logística Reversa como solução para o problema do lixo eletrônico: benefícios ambientais e financeiros. Rio de Janeiro: Qualitymark, 2010.112 p.

MOURA, Adriana Maria Magalhães de. Governança ambiental no Brasil: instituições, atores e políticas públicas. Org. Brasília: IPEA, 2016. 352 p.

MPSP. Ministério Público do Estado de São Paulo. Ato Normativo n. 552/08 instituiu o Grupo de Atuação Especial de Defesa do Meio Ambiente (GAEMA) e a Rede de Atuação Protetiva do Meio Ambiente. MPSP, $2008 . \quad$ Disponível em:< http://www.mpsp.mp.br/portal/page/portal/cao urbanis mo e meio ambiente/rede gaema>. Acesso em: 15 ago. 2020.

NUNES, Isabel Correa; NITZ, Andrey Lesan; FAGUNDES, Alexandre Borges; PEREIRA, Delcio; BEUREN, Fernanda Hansch. Impactos Sociais, ambientais e econômicos do lixo eletrônico: Uma revisão na literatura visando um Sistema ProdutoServiço. XXXVII Encontro Nacional de Engenharia de Produção, 2017. Disponível em:<
http://www.abepro.org.br/biblioteca/TN STO 242405 34174.pdf>. Acesso em 14 nov. 2020.

RUA, Maria das Graças. Políticas Públicas. 3 ed. Florianópolis: Departamento de Ciências da Administração/UFSC: Brasília: CAPES: UAB, 2014. 130 p.

SEADE. Fundação Sistema Estadual de Análise de Dados. PIB - Municípios Paulistas 2002-2016. São Paulo: SEADE, 2017. Disponível em:< https://portalgeo.seade.gov.br/wpcontent/uploads/2019/02/PIB Municipal ed2019.pdf>. Acesso em: 07 jun. 2019.

SEIFFERT. Mari Elizabete Bernardini. Gestão Ambiental: instrumentos, esferas de ação e Educação Ambiental. São Paulo: Atlas Oficina de Textos, 2009. 310 p.

UNEP. United Nations Environment Program. Recycling - from e-waste to resources. New York: UNEP, 2009. 120 p.

XAVIER, Lúcia Helena.; CARVALHO, Tereza Cristina. Gestão de resíduos eletroeletrônicos. $1^{\mathrm{a}} \mathrm{Ed}$. Rio de Janeiro: Elsevier, 2014. 218 p. 